\title{
Derrida e a Linguística Estrutural - uma leitura do capítulo 1 de Gramatologia
}

\author{
Alcides Cardoso Santos \\ Universidade Estadual Paulista "Júlio de Mesquita Filho" (UNESP), \\ Araraquara, São Paulo, Brasil \\ alcides@fclar.unesp.br \\ https://orcid.org/0000-0002-1124-2246
}

DOI: $\underline{\text { http://dx.doi.org/10.21165/el.v47i2.2058 }}$

\begin{abstract}
Resumo
Em sua leitura do Curso de Lingüistica Geral, Derrida ressalta a grande contribuição de Saussure ao afirmar a natureza arbitrária e diferencial do signo linguístico. Derrida também percebe, porém, que, se por um lado o conceito de diferença foi fundamental para Saussure romper com a concepção "natural" de linguagem, por outro, ao introduzir o conceito de valor e hipostasiar a superioridade da fala sobre a escrita, Saussure reproduz o pensamento metafísico binário e hierarquizado. A partir da linguística saussuriana, Derrida propõe, então, uma ciência geral do "grama" como desconstrução da violência originária fundada na noção de valor.
\end{abstract}

Palavras-chave: Saussure; Derrida; "grama”; diferença; valor.

\section{Derrida and Structural Linguistics - a reading of chapter 1 of Gramatology}

\begin{abstract}
In his reading of the Course in General Linguistics, Derrida praises Saussure's statement of the arbitrary and differential nature of the linguistic sign as a great achievement. However, Derrida also notices that if, on the one hand, the concept of difference was fundamental to enable Saussure to break with a naturalistic conception of language, on the other hand, by introducing the concept of value and hypostasizing the superiority of speech over writing, Saussure echoes western metaphysics' binary and hierarchical thought. Departing from Saussurian linguistics, Derrida proposes, then, a science of the "gramme" as a deconstruction of the original violence generated by the concept of value.
\end{abstract}

Keywords: Saussure; Derrida; "gramme"; difference; value.

Escrever sobre Saussure para uma revista de linguística pode ser, para quem tem um percurso acadêmico voltado aos estudos da Literatura, bastante arriscado e, mesmo me lembrando dos "Provérbios do Inferno", de Blake (ERDMAN, 1988, p. 35), ainda assim contrariarei o velho bardo e seguirei os passos desta velha e rica senhora, a Prudência. Me aterei a algumas questões específicas que Derrida levanta em sua leitura do Curso de Linguística Geral (1995) para fundamentar uma discussão desconstrutora marcando o duplo gesto da desconstrução de homenagem e crítica ao texto lido - do legado saussuriano para a linguística e para as humanidades em geral.

Assim como nas reflexões de Derrida, nas quais muito me inspiro, esta reflexão será marcada por um tom exploratório mais que qualquer tentativa de chegar a uma verdade ou conclusão final sobre o assunto e da mesma forma que Derrida sempre falou, no âmbito da política, em uma democracia por vir, também seguiremos as pegadas de Derrida em uma reflexão ainda por vir sobre Saussure. Começaremos, então, por uma 
breve apresentação dos aspectos mais importantes do pensamento de Derrida, de sua "desconstrução", ou melhor, "desconstruções", como ele mesmo assim se referia ao seu trabalho, com o intuito não tanto de fazer uma apresentação do pensamento da desconstrução, mas de trilhar novamente o caminho que levou o filósofo franco-argelino ao Curso de Linguística Geral no intuito de mostrar como este encontro não foi uma escolha ou um acaso, mas fundamentalmente uma necessidade.

Em seguida, nos deteremos na leitura que Derrida faz do Curso no capítulo 1 de sua Gramatologia (1973), enfatizando alguns pontos no intuito de chegar mais diretamente ao ponto central desta reflexão, a questão da centralidade da voz no pensamento de Saussure e sua pertença ao que Derrida (seguindo Heidegger) chama de Metafísica ocidental.

Num terceiro momento trataremos do que Derrida chama de uma "teoria geral da escritura" e discutiremos a importância deste termo para a desconstrução, demonstrando que a desconstrução não se assemelha a qualquer forma de destruição e sim à construção de um pensamento que possa dar continuidade às questões fundantes e fundamentais elaboradas pelos grandes pensadores da cultura ocidental. Tal continuidade se dá, nos textos de Derrida, por meio da leitura atenta dos textos fundadores do pensamento ocidental e do aprofundamento dessas questões a um grau ou extensão já antevista ou anunciada pelos seus textos, mas não elaborada formalmente ou assumida pelos seus autores, em um movimento de fazer o texto lido chegar a conclusões que, muitas vezes, contrariam diretamente as proposições superficiais ou iniciais desses textos.

É neste sentido que podemos também falar da desconstrução de Derrida como uma forma, talvez um tanto nietzscheana, de homenagem a estes pensadores e, com certeza, este é o caso de leitura que Derrida faz de Saussure.

\section{A “desconstrução" de Derrida}

Derrida continua a ser um autor muito comentado, bastante criticado, mas infelizmente pouco lido. Sua reflexão, que tem início nos anos 60, foi marcada por revisitações a textos e autores clássicos da filosofia ocidental, como Platão, Rousseau, Husserl, Kant, Hegel, Nietzsche, Heidegger, assim como a textos clássicos da literatura do ocidente, como Shakespeare, Joyce, Celan, Mallarmé, Valéry, Artaud, sem falar em Freud, presença constante nas revisitações de Derrida.

A obra produzida por Derrida a partir de tais revisitações soma algo por volta dos 100 títulos, que lhe garantiram o lugar como um dos filósofos mais importantes do século $\mathrm{XX}$. Suas reflexões tiveram e ainda têm um alcance que ultrapassou em muito os muros da filosofia - onde, diga-se de passagem, Derrida nunca foi bem aceito -, para adentrar os campos da estética, teoria da literatura, psicologia, epistemologia, teoria dos gêneros, feminismo, dentre os vários campos onde sua reflexão foi influente. Isto sem falar na disseminação popular de suas ideias, que muito contribuíram para os movimentos da contracultura, do pós-modernismo, dos estudos culturais, tendo grande influência no cinema, nas artes visuais e até mesmo na mídia televisiva.

Tida por alguns como estratégia política, para outros como estratégia intelectual e para outros ainda como um modo de leitura (CULLER, 1997), podemos nos perguntar: qual o interesse de Derrida em revisitar a herança filosófica e cultural do ocidente? O que 
haveria de "novo" nestes textos que já não teria sido dito, escrito e perscrutado ao longo dos séculos e de tantas leituras?

Longe de querer resumir aqui o pensamento de Derrida - que, aliás, apresentaria de cara problemas como: Por onde começar? Qual é o centro do seu pensamento? Qual é o seu método?, longe, então, de querer resumir o pensamento de Derrida, gostaríamos de apresentar, ainda que com o risco de superficialidade, as questões que levaram o filósofo franco-magrebino à releitura destes textos e à releitura de Saussure.

O "foco" (se assim podemos nos referir a uma certa recorrência de temas nos textos da desconstrução) das releituras de Derrida diz respeito fundamentalmente a uma forma de pensar que se cristaliza no Ocidente a partir da formação de um cânone de leituras dos textos platônicos, mais especificamente àquilo que se conhece como "platonismo" e que pode ser percebido tanto na cultura como no pensamento conceitual ocidentais. Tal forma cristalizada de pensar diz respeito também - e, talvez, fundamentalmente - ao processo histórico de incorporação da racionalidade grega pela fé cristã a partir de Santo Agostinho e, posteriormente, por São Tomás de Aquino. Esta junção, denominada por Heidegger de era da metafísica, não somente cria os valores fundantes da cultura ocidental, mas estabelece - o que é bem mais importante - a maneira de pensar que caracteriza o ocidente em todos os seus aspectos.

O foco, então, de Derrida nestas releituras incidirá sobre a relação genética entre diferença e valor. Comecemos pela questão da diferença como fundamento do pensamento ocidental.

O modo de pensar que a chamada Metafísica estabelece tem seu fundamento na ideia e no conceito de diferença. Primeiramente, no platonismo, tratava-se de estabelecer a diferença entre o real e o ideal, garantindo as condições para que o pensamento pudesse trilhar seu destino do primeiro ao segundo naturalmente, ou seja, para que o ideal pudesse ser vislumbrado a partir do real. As características da idealidade - o bem e a verdade são estabelecidas por Platão em seus Diálogos a partir da maiêutica socrática, cabendo a seu discípulo Aristóteles definir posteriormente as leis que regem o conhecimento do mundo real, leis necessárias a toda e qualquer forma de pensamento.

A diferença estabelecida por Platão entre o mundo ideal e o real se torna a pedra de toque do conceito aristotélico de identidade que, juntamente com o conceito de nãocontradição, estabelece as bases para a ciência ocidental. Assim, a hipóstase do ideal se torna o modelo que regerá o pensamento filosófico por muitos séculos vindouros.

O Cristianismo também estabelece a diferença como base de sua fé, não mais entre o mundo ideal e o real, mas entre o divino e o humano, este último visto, em muitos momentos da história - como no Protestantismo dos séculos XVI e XVII - como materialização do mal. Apesar da comunicabilidade entre essas duas instâncias, a crença na diferença genética entre divino e humano e na anterioridade do primeiro sobre o último é inquestionável à fé cristã, tornando-se o pilar de todas as igrejas derivadas do Cristianismo.

A junção do topos uranus platônico com o céu cristão se dá quase "naturalmente" nos primeiros séculos da Era Comum e se estabelece não somente como a visão de mundo predominante, mas - o que nos interessa aqui - como uma forma de pensar que, ao mesmo tempo em que estabelece os fundamentos do mundo ocidental em todas as suas vertentes (da música à teologia, da arquitetura à literatura, da medicina ao esoterismo), também 
sobredetermina as suas possibilidades, reduzindo o seu escopo ao já conhecido, como diria Heidegger (2006, p. 63), "Em toda parte, o modo cunhado pela Metafísica de o homem representar em proporções apenas encontra o mundo construído pela Metafísica”. O filósofo Martin Heidegger se debruçou sobre esta questão em praticamente toda a sua obra, se perguntando se haveria possibilidade de pensarmos, de fato, diante desta pesada e poderosa herança. A partir deste momento, então, me referirei a esta junção do platonismo com o Cristianismo e sua herança como sobredeterminação do pensamento ocidental pelo termo que lhe aplica Heidegger, isto é, como a Metafísica Ocidental.

Passemos agora, então, à associação entre a diferença, como suporte do pensamento ocidental, e a questão do valor.

Ao associar ao mundo ideal os valores do bem e da verdade, Platão inicia uma tradição de hierarquização das diferenças que se dá em dois momentos distintos, porém interligados congenitamente. Em primeiro lugar, trata-se da oposição das diferenças em pares, estabelecendo a dualidade contrastiva da sua teoria dos dois mundos bem como o conceito de identidade e de não-contradição que fundamentam a diferença epistemológica entre o ideal e o real. Assim, no platonismo, o ideal não somente se diferencia do real, mas a ele se opõe, assim como no cristianismo o divino não somente se diferencia do humano, mas a ele se opõe. As oposições garantem a existência das identidades e delas se nutrem, num processo de retroalimentação que funda e comanda a maneira ocidental de pensar e a própria história do ocidente.

Quando dissemos que Platão inicia a tradição de hierarquização das diferenças, nos referimos ao fato de que, associado ao conceito de diferença opositiva, surge indissociavelmente o conceito de valor, isto é, a ideia de que um dos lados destas oposições terá sempre um valor maior, superior ao outro, fazendo com que a balança das diferenças sempre pese mais para um lado do que para o outro. Já na República, no Fedro, n'O Banquete e em outros diálogos, o discípulo do Sócrates deixa clara a superioridade do ideal sobre o real a partir do estabelecimento de que o bem e a verdade só podem ser pensados idealmente, causando um rebaixamento do real e do sensorial em função do racional e do transcendente.

O estabelecimento do conceito de verdade como valor que comanda a hierarquia das diferenças opositivas e fundamenta a possibilidade de distinção entre o verdadeiro e o falso se torna, então, a arquioposição que comanda a história do ocidente e guia nossa forma de pensar desde então, caracterizando a história do ocidente como uma história de dominação e violência, teórica ou religiosa, em nome da verdade ou de Deus. Sendo uma arquioposição, como dissemos, a oposição verdade/mentira comanda a forma ocidental de pensar, pois não importa qual ideia, conceito ou aspecto seja colocado em questão, o que importa é em qual lado da oposição ele será colocado. Foi esta a aventura do espírito que Hegel buscou entender por meio do seu conceito de história e aufhebung.

\section{Derrida e Saussure}

A reflexão sobre a questão da verdade é uma recorrência no pensamento de Derrida, que procurou reler nos textos fundamentais do ocidente o duplo gesto de adesão e contestação das verdades estabelecidas, gesto que Derrida percebe ao perseguir hesitações destes textos entre as posições (teóricas e políticas) assumidas abertamente e os desdobramentos de certas afirmações que, amiúde, revelam uma lógica dissonante das 
posições assumidas pelo texto. Esta é a estratégia da leitura desconstrucionista, que Derrida levou a cabo em suas releituras.

A partir desta reflexão sobre a verdade e sua relação genética com a Metafísica Ocidental, Derrida percebe que a verdade se desdobra de um conceito a uma espécie de campo, no qual vários conceitos foram historicamente abrigados, tais como, o espírito, a transcendência, a consciência, a voz, o homem, o dia, o branco e o lado direito, entre muitos outros, aos quais foram opostos como não-verdade os conceitos de corpo, imanência, paixões, a escrita, a mulher, a noite, o negro e o lado esquerdo. Só para lembrar, o lado esquerdo - em italiano chamado de "sinistra" - foi associado à feitiçaria na idade média e não foram poucos os hereges queimados em fogueiras públicas por usarem a mão esquerda mais do que a direita.

É claro que, historicamente, os conceitos e valores mudaram de lado no campo da verdade, isto é, migraram da verdade para a não-verdade e vice-e-versa como consequência do movimento da história, por exemplo, a mulher no discurso feminista dos anos 60 (os anos da "mística feminina"), mas se tratou sempre de uma mudança de lado, sem afetar o funcionamento do campo da verdade. É verdade que em tempos de pósmodernidade haveria muito a discutir sobre o enfraquecimento do conceito e da força de valor da verdade, como diria Gianni Vattimo, mas esta é uma discussão bastante longa que não nos interessará aqui.

A atração de Derrida por Saussure se dá no mesmo sentido que sua atração pelos pensadores que estabeleceram a tradição metafísica ocidental, ou seja, Derrida procura entender como esses pensadores ao mesmo tempo em que foram revolucionários, abriram fronteiras para o pensamento, por outro lado, não o foram o suficiente a ponto de questionar o fundamento de seu pensamento, o conceito-valor de verdade. Derrida vai perceber este questionamento em aspectos geralmente negligenciados nestes textos, em observações passageiras ou notas de rodapé aparentemente sem grande importância que, lidas em seu potencial disruptor, podem chegar a minar as afirmações explícitas do texto. Este é o caso de um texto brilhante de Derrida sobre a questão da verdade n'A origem $d a$ obra de arte, de Heidegger (1987a, p. 255 et passim), em que Derrida começa sua releitura perguntando a Heidegger o que é um par, ou sobre a releitura da Crítica do juízo de Kant, em que Derrida reflete sobre os parerga, aos quais o filósofo alemão dedica uma nota em sua Crítica, se perguntando se esses (os parerga) fariam parte ou não da obra de arte (DERRIDA, 1987b, p. 15 et passim).

A lista de autores sobre os quais Derrida escreveu é extensa demais para que tentemos sequer fazer uma glosa, mas o que importa aqui é perceber que as suas releituras fazem, ao mesmo tempo, uma homenagem a estes autores e uma leitura crítica, buscando os pontos que poderiam ter sido aprofundados para se chegar a um questionamento do fundamento do pensamento ocidental, o conceito-valor de verdade. É assim que Derrida, então, relê o Curso de Linguística Geral, como uma obra revolucionária que abriu fronteiras para o pensamento ocidental, mas que, em alguns pontos, não levou sua reflexão ao ponto extremo de questionar suas bases onto-teológicas.

A questão poderia ser apresentada esquematicamente da seguinte forma: por um lado, Saussure estabelece revolucionariamente a imotivação do signo linguístico, isto é, a ausência de elo causal entre o significante e significado, rompendo com a ideia de naturalidade entre mundo e referência, uma discussão que remonta ao Crátilo de Platão. Ao estabelecer a artificialidade do signo linguístico, sua desvinculação com o mundo e 
sua autonomia como construção cultural, Saussure estabelece os contornos da linguística moderna e do próprio estruturalismo. A arbitrariedade na relação entre o conceito e sua imagem acústica possibilitou um avanço enorme no estudo da produção e uso da língua como instrumento de comunicação, pois permitiu o entendimento dos processos pelos quais cada sociedade engendra seus significantes de acordo com sua cultura e sua língua.

Não me preocuparei em relembrar aqui os argumentos de Saussure desenvolvidos no seu Curso, tampouco me aterei à discussão sobre a transcrição de suas aulas feita por Charles Bally e Albert Sechehaye e a "fidelidade" aos argumentos originais de Saussure. Tampouco me referirei à produção dos Anagramas, posteriormente publicados por Starobinski e sua "problematização" da ascendência da sincronia sobre a diacronia. Apenas me deterei na reflexão que Derrida faz sobre a aderência de Saussure - um tanto veemente, diga-se de passagem - à primazia da voz na estrutura do signo linguístico e como esta aderência se relaciona ao conceito-valor de verdade.

A releitura que Derrida faz do Curso começa com o privilégio dado à phoné no sistema de pensamento saussuriano, ao qual Derrida (1973, p. 9, grifo do autor) se refere:

[...] O privilégio da phoné não depende de uma escolha que teria sido possível evitar. [...] O sistema do "ouvir-se-falar" através da substância fônica - que se dá como significante não-exterior, não-mundano, portanto não-empírico ou não-contingente - teve de dominar durante toda uma época a história do mundo, até mesmo produziu a ideia de mundo, a ideia de origem do mundo a partir da diferença entre o mundano e o não-mundano, o fora e o dentro, a idealidade e a não-idealidade, o universal e o não-universal, o transcendental e o empírico, etc.

O que Derrida quer mostrar é que Saussure dá continuidade a uma tradição de pensamento ocidental (a metafísica, como já dissemos) que rebaixa a escritura ao descrevê-la como "tradutora de uma fala plena e plenamente presente (presente a si, ao seu significado, ao outro, condição mesma do tema da presença em geral)" (Ibidem, p. 9, grifo do autor), e que já nas primeiras cenas do Fedro se mostra na desconfiança de Sócrates em relação ao discurso de Lísias sobre o amor, que Fedro traria em forma escrita, sob as mangas de sua toga.

A desconfiança com a linguagem escrita se instaura, a partir de então, como um anátema, que ganha reforço com a promessa, em Coríntios II, 3-6, de um novo testamento, "não da letra, mas do espírito; porque a letra mata e o espírito vivifica" (2003, capítulo 3, versículo 6), retomado por Santo Agostinho em sua explicação do mistério da Graça, em suas Confissões.

A desconfiança em relação à escrita, situada originalmente no lado da nãoverdade, a lembrarmos a famosa alegoria da caverna de Platão n'A República, se dissemina no ocidente e mesmo as ciências que dela dependem fundamentalmente, como a Filosofia, a concebem, quando muito, como instrumento ou técnica, desprovida de qualquer valor em si. Fato curioso, para não dizer paradoxal, este, o rebaixamento da escrita na cultura ocidental, uma cultura que historicamente afirmou sua superioridade em relação a outras culturas e outros povos justamente pelo seu caráter letrado. Fato que, não por acaso, nos faz pensar no recalque freudiano.

Mas voltemos à reflexão de Derrida sobre o privilégio da voz no Curso. Na primeira parte de sua argumentação, intitulada "O significante e a verdade", o filósofo afirma: 
Todas as determinações metafísicas da verdade [...] são mais ou menos imediatamente inseparáveis da instância do logos ou de uma razão pensada na descendência do logos, em qualquer sentido que seja entendida: no sentido pré-socrático ou no sentido filosófico, no sentido do entendimento infinito de Deus ou no sentido antropológico, no sentido préhegeliano ou no sentido pós-hegeliano. (DERRIDA, 1973, p. 13).

O logos, pensamento não expresso, interior, se caracteriza pela sua proximidade à idealidade, uma vez que é anamnese, rememoração da verdade ideal pela alma encarnada no mundo real, diria Platão.

Porém, este pensamento próximo da idealidade também precisa de um meio de expressão que esteja tão próximo quanto possível da idealidade, que Platão define como a phoné, a voz que garante a fidelidade da expressão ao pensamento. A associação genética da verdade ao logos, explica Derrida, também incluiria a phoné, a voz que “estaria imediatamente próxima daquilo que, no 'pensamento' como logos, tem relação com o 'sentido'; daquilo que o produz, que o recebe, que o diz, que o 'reúne"” (Ibidem, p. 13). Resumidamente, a verdade se estabelece originariamente na tradição ocidental como pensamento (dianoia) que tem expressão "natural" na voz, como autoafecção do "ouvir-se-falar", garantindo assim a "naturalidade" na expressão da verdade pela forma presencial da voz. A associação do logos com a phoné fundamenta qualquer possibilidade de conhecimento da verdade e estabelece a axiologia da tradição metafísica, o que leva Derrida a usar o termo "fonologocentrismo" para se referir a esta tradição que, de tão longa e sedimentada, deixou de ser pensada em seus fundamentos e suas raízes ontoteológicas.

A definição que o próprio Saussure dá do significado como sentido ou conceito traduz o aspecto psicológico, interior, presencial, de sua teoria linguística sincrônica, em contraposição ao significante ou imagem acústica, pensado como exterioridade, como momento posterior à presença plena do sentido. Um dentro (significado) e um fora (significante), embora em mútua dependência, são distintamente estabelecidos como balizas de sua teoria linguística.

Estabelecendo o significante como externo, posterior e oposto à interioridade do significado, garantido pela proximidade da voz à verdade ideal, Saussure também nos permite pensar em outros significantes, tais como o signo natural e, sobretudo e principalmente, o significante escrito. Dizemos principalmente porque este não será um significante qualquer entre outros, não somente porque dá a identidade à cultura ocidental, mas também porque esteve sempre colado à hipostática plenitude da voz e da presença, como rastro ou espectro que se quer conjurar.

Conjurar pode parecer um termo forte, mas os termos com que Saussure se refere à escrita demonstram, na visão do linguista genebrino, a violência deste sistema "estranho ao sistema interno" que "se mistura tão intimamente com a palavra falada, da qual é a imagem, que acaba por usurpar-lhe o papel principal" (SAUSSURE, 1995, p. 33), como a ela se refere Saussure no famoso capítulo VI do Curso, intitulado "Representação da língua pela escrita". Os termos usados por Saussure para se referir à ingerência da escrita sobre a fala (se misturar, usurpar e, em outro momento, como a "filha bastarda" da fala) evidenciam não somente a hierarquização da diferença entre fala e escrita, mas um certo rancor contra esta última pelo seu papel central na cultura ocidental. Ora, a característica central da cultura ocidental é a de ser uma civilização letrada e é, portanto, compreensível que a escrita esteja no seu centro. 
Assim como Saussure em sua argumentação contra a palavra escrita, Derrida mostra que Rousseau, por razões semelhantes, também acusa, em seu Ensaio sobre a origem das línguas de 1781, a articulação gramatical de violência contra a naturalidade melódica das línguas em seu estado original. Também Levi-Strauss, em 1955, no seu Tristes trópicos, apresenta seus argumentos contra a violência da cultura escrita sobre as culturas não letradas, no caso da cultura branca sobre os índios Nhambiquara do Brasil. Em outras palavras, Saussure parece fazer parte desta linhagem de pensadores que tratam a palavra escrita com desconfiança e rancor pela sua condição externa, não confiável (cf. A República, Fedro), bastarda e usurpadora, como um utensílio (ou uma técnica) que deveria ser neutro, utilitário, mas que se torna portador de um mal que vem de fora com toda a ameaça que o "fora" traz à hipostasia da plenitude do dentro, do em-si, da voz e da consciência, como diz Derrida: “....a escritura, a letra, a inscrição sensível, sempre foram consideradas pela tradição ocidental como o corpo e a matéria exteriores ao espírito, ao sopro, ao verbo e ao logos." (Op. cit., p. 42)

A diferença entre fala e escrita, que Saussure estabelece como fundamento de sistema linguístico, é acompanhada pela questão do valor do significante linguístico que, por ser posterior e exterior, funciona contrastivamente a outros significantes (sonoro, escrito, visual, pictórico) dentro do sistema, possibilitando o funcionamento do sistema linguístico. Porém, se o valor do significante se dá, num primeiro, de forma horizontal, entre significantes, é verticalmente, na hierarquia entre os significantes e no consequente rebaixamento do significante escrito em relação a outros significantes - sobretudo o sonoro -, é, enfim, em nome da pureza hipostática do significante falado que o valor assume sua posição central no sistema saussuriano, como explica Derrida (1973, p. 48):

Declaração de princípio, voto piedoso e violência histórica de uma fala sonhando sua plena presença a si, vivendo a si mesma como sua própria reassunção: autodenominada linguagem, autoprodução da fala dita viva, capaz, diria Sócrates, de se dar assistência a si mesma, logos que acredita ser para si mesmo seu próprio pai, elevando-se assim por cima do discurso escrito, infans e enfermo por não poder responder quando é interrogado e que, tendo sempre "necessidade de assistência de seu pai" [...] (Fedro 275) deve pois ter nascido de um corte, de uma expatriação primeira, consagrando-o à errância, ao cegamento, ao luto.

O valor vertical, que produz a hipóstase da fala plena e o rebaixamento da escrita faz com que o Curso reproduza, como percebe Derrida, o mesmo movimento da tradição metafísica ocidental de rebaixamento da escrita em nome de uma fala pura, fato que, em boa parte, obstrui o grande avanço que Saussure já havia realizado com a percepção da arbitrariedade do signo e de seu caráter diferencial.

Mas o que Derrida pretende com tal releitura de Saussure? Não se trata, como veremos, de reafirmar o valor da escrita sobre a fala, o que seria apenas reproduzir a hierarquização que acompanha a diferença no sistema linguístico saussuriano. Não se trata, tampouco, de anular as diferenças entre fala e escrita, o que seria tanto utópico quanto ingênuo. Derrida propõe, como veremos a seguir, uma ciência do gramma, a que ele denomina gramatologia. 


\section{Gramatologia como ciência linguística?}

O que Derrida reclama a Saussure é o fato de a grande abertura possibilitada pelo estudo da língua como sistema diferencial, não natural, entre signos, ser, em última instância, guiada por um conceito-valor de verdade articulado sobre a unidade do logos com a phoné e o fato de que

[...] a intenção que institui a linguística geral como ciência permanece, sob este ponto de vista, na contradição. Um propósito declarado confirma, com efeito, dizendo o que é aceito sem ser dito, a subordinação da gramatologia, a redução histórico-metafísica da escritura à categoria de instrumento subordinado a uma linguagem plena e originariamente falada. Mas um outro gesto (não dizemos um outro propósito, pois aqui, o que não segue sem dizer é feito sem ser dito, escrito sem ser proferido) liberta o porvir de uma gramatologia geral, de que a linguística fonológica seria somente uma região dependente e circunscrita. (DERRIDA, 1973, p. 36).

Dito de outra forma, se Saussure "[...] retoma a definição tradicional de escritura que já em Platão e Aristóteles se estreitava ao redor do modelo da escritura fonética e da linguagem de palavras" (Ibidem, p. 37), ele assim fazendo reafirma a tradição metafísica por um gesto inequívoco. Porém, seu texto escreve o que não diz, sugere o que não afirma, ou seja, mesmo estabelecendo o significante fônico como representante da voz e da consciência/pensamento e rebaixando ou deslegitimando os outros significantes, sobretudo o escrito, seu texto antevê a possibilidade de uma ciência dos signos em geral, não subordinada à hierarquia da phonéllogos, como diz Derrida (Ibidem, p. 37, grifo do autor), aprofundando o escopo da arbitrariedade do signo linguístico, "A tese do arbitrário do signo [...] deveria proibir a distinção radical entre signo linguístico e signo gráfico.”.

Se aprofundarmos as consequências da caracterização da língua como uma rede de significantes diferenciais arbitrários - a grande contribuição de Saussure ao que Heidegger chamou de epoché da metafísica ocidental - entenderemos o argumento de Derrida de que a exclusão do significante escrito da interioridade da verdade e do sentido, a sua exclusão da idealidade da verdade/logos/phoné contradiz a própria proposição da Semiologia como uma ciência geral de signos de Saussure, na qual "o significante gráfico remete ao fonema através de uma rede com várias dimensões que o liga, como todo significante, a outros significantes escritos e orais, no interior de um sistema "total", ou seja, aberto a todas as cargas de sentido possíveis. É da possibilidade deste sistema total que é preciso partir." (Ibidem, p. 55).

A "desconstrução" da linguística saussuriana implicaria - como em todas as leituras desconstrutivistas - a manutenção das conquistas teóricas de Saussure (a tese da arbitrariedade do signo) com o aprofundamento dos pontos que Saussure não chegou a proferir, mas que seu texto insiste em sugerir (a teoria geral dos signos), ou seja, a manutenção da diferença, porém sem o valor. O ponto de partida de tal desconstrução seria, sem dúvida, o esvaziamento do valor da substância fônica em relação a outras formas de significante. Esvaziando-se a idealidade da qual a phoné seria representante legítima e direta, a relação entre o que Derrida chama de significado transcendental e os significantes que o representam no mundo sensível continuaria sendo uma relação diferencial, mas deixaria de ser valorativa. Não havendo um significado verdadeiro e original da qual a língua seria a portadora, o jogo dos significantes aconteceria como um sistema de rastros que não permitiria a hipóstase de um significado pleno, ideal, do qual 
a fala seria a legítima representante e a escrita a filha bastarda. Derrida usa o termo "rastro" para mostrar que, se por um lado é impossível simplesmente abstrair do pensamento da idealidade (como diria Heidegger, é impossível sair da metafísica), por outro lado é possível pensar o rastro antes do ente, isto é, pensar o rastro como sistema, não como índice. Dito de outra forma, pensar o rastro como sistema seria pensar a linguagem como um sistema de rastros (ou significantes) que não reconduzem a qualquer forma de plenitude, como explica Derrida (Ibidem, p. 80): "Esta impossibilidade de reanimar absolutamente a evidência de uma presença originária, remete-nos, pois, a um passado absoluto. É isto que nos autorizou a denominar rastro o que não se deixa resumir na simplicidade de um presente.".

O rastro derridiano, aquilo que não sendo completamente ideal ou sensível, permite o acontecimento das diferenças sensíveis e dos sentidos inteligíveis (que Derrida, em outros textos, também chamará de diffërance) poderia ser uma forma produtiva de pensar a diferença saussuriana. Embora esta forma de ler e pensar a diferença não seja proferida por Saussure com clareza ou convicção, ela pode ser lida no seu texto, nas sugestões, interditos e entrelinhas de sua escrita pois, se levada ao cabo e ao termo, a diferença saussuriana poderia ser pensada não como um fato ou um conceito, mas como um processo, um produzir constante de diferenças sensíveis. Sem o valor associado à matéria fônica, a diferença saussuriana não possibilitaria a hierarquização dos significantes que, assim, entrariam no jogo da língua sem reservas ou prescrições, a língua adquiriria o rumor que Barthes (2004) preconizava.

A esta diferença ou rastro Derrida (Ibidem, p. 11) também denomina grama ou grafema, um elemento irredutível a qualquer forma de experiência (como o espaçamento, noção que Derrida empresta de Mallarmé) “que deveríamos proibir-nos a nós mesmos de definir no interior do sistema de oposições da metafísica, (d)aquilo que portanto não deveríamos nem mesmo denominar a experiência em geral, nem tampouco a origem do sentido em geral.".

Produtor de toda forma ou manifestação de diferenças, este rastro não se prenderá à ordem do sensível e tampouco do inteligível, não podendo ser contido pela lógica conceitual ou reconhecida pela lógica da não-contradição. O rastro seria, então, uma origem sem origem, uma voz sem verdade, e se misturaria com os outros significantes, desvalidos da verdade e do logos tanto quanto o significante escrito. Neste intercâmbio sígnico, nesta celebração do prazer do texto, como diria Barthes, o valor deixaria de reger a semiose e a Semiologia saussuriana poderia então se tornar uma gramatologia, uma ciência geral do signo, de todos os signos.

Assim se refere Derrida (Ibidem, p. 77) ao rastro ou diferença (que, neste trecho, usa o termo diferência):

O rastro (puro) é a diferência. Ela não depende de nenhuma plenitude sensível, audível ou visível, fônica ou gráfica. É, ao contrário, a condição destas. Embora não exista, embora não seja nunca um ente-presente fora de toda plenitude, sua possibilidade é anterior, de direito, a tudo que se denomina signo (significado/significante, conteúdo/expressão, etc.), conceito ou operação, motriz ou sensível. Esta diferência, portanto, não é mais sensível que inteligível, e ela permite a articulação dos signos entre si no interior de uma mesma ordem abstrata - de um texto fônico ou gráfico, por exemplo - ou entre duas ordens de expressão. Ela permite a articulação da fala e da escrita - no sentido corrente - assim como ela funda a oposição metafísica entre o sensível e o 
inteligível, em seguida entre significante e significado, expressão e conteúdo, etc. Se a língua já não fosse, neste sentido, uma escritura, nenhuma "notação" derivada seria possível e o problema clássico das relações entre fala e escritura não poderia surgir.

Como a ursprache benjaminiana, a diferência derridiana faria de Babel não mais um castigo, senão uma utopia, o sonho de uma linguagem que abrigaria todas as formas de diferença sem valor e que instauraria o prazer, o desregramento como gozo. Para finalizar, num gesto de amorosa traição a Derrida e a Saussure, termino com as palavras de Barthes (2004, p. 95, grifo do autor) sobre esta utopia da linguagem babélica, com a ressalva de que substituirei as duas ocorrências da palavra rumor por rastro:

E a língua, pode deixar rastros? Falada, ela permanece sempre condenada ao balbucio; escrita, ao silêncio e à distinção dos signos: de qualquer modo fica ainda demasiado sentido para que a língua realize um gozo que seria próprio a sua matéria. Mas o que é impossível não é inconcebível: o rastro da língua forma uma utopia.

\section{REFERÊNCIAS}

BARTHES, R. O rumor da língua. Tradução de Mario Laranjeira. São Paulo: Martins Fontes, 2004.

BÍBLIA DE JERUSALÉM. 2. impr. São Paulo: Paulus, 2003.

CULLER, J. Sobre a Desconstrução. Tradução de Patricia Burrowes. Rio de Janeiro: Rosa dos Ventos, 1997.

DERRIDA, J. Restitutions. In: . The Truth in Painting. Tradução de Geoff Bennington e Ian McLeod. Chicago: The University of Chicago Press, 1987a.

Parergon. In: . The Truth in Painting. Tradução de Geoff Bennington

e Ian McLeod. Chicago: The University of Chicago Press, $1987 \mathrm{~b}$.

Gramatologia. Tradução de Miriam Schnaiderman e Renato Janine Ribeiro. São Paulo: Perspectiva, 1973.

ERDMAN, D. (Org.). The Complete Poetry and Prose of William Blake. New York: Anchor Books, 1988.

HEIDEGGER, M. A superação da metafísica. In: HEIDEGGER, M. Ensaios e Conferências. Tradução de Emmanuel Carneiro Leão, Gilvan Fogel e Marcia Sá Cavalcante Schuback. 3. ed. Petrópolis: Vozes; Bragança Paulista: Editora Universitária São Francisco, 2006.

SAUSSURE, F. Curso de Linguística Geral. Tradução de Antônio Chelini, José Paulo Paes e Izidoro Blikstein. São Paulo: Cultrix, 1995.

Recebido em: 31/10/2017

Aprovado em: 21/03/2018 